\title{
Supervisors of Installation, Maintenance, and Repair Workers
}

National Cancer Institute

\section{Source}

National Cancer Institute. Supervisors of Installation, Maintenance, and Repair Workers. NCl Thesaurus. Code C122510.

Workers who directly supervise and coordinate the activities of mechanics, installers, and repairers. 